\title{
GMR
}

\section{Association between the interleukin-1ß C-511T polymorphism and periodontitis: a meta-analysis in the Chinese population}

\author{
H.F. Wang ${ }^{1 *}$, F.Q. He ${ }^{2 *}$, C.J. Xu ${ }^{1}$, D.M. Li ${ }^{1}$, X.J. Sun ${ }^{1}$, Y.T. Chi ${ }^{1}$ and W. Guo ${ }^{3}$ \\ ${ }^{1}$ Department of Oral Medicine, Xiangya Hospital, Central South University, \\ Changsha, China \\ ${ }^{2}$ Department of Prosthodontics, Changsha Stomatological Hospital, Changsha, \\ China \\ ${ }^{3}$ Department of Pathology, Xiangya Hospital, Central South University, Changsha, \\ China \\ *These authors contributed equally to this study. \\ Corresponding author: C.J. Xu \\ E-mail: xyxucj77@126.com
}

Genet. Mol. Res. 16 (1): gmr16019315

Received September 20, 2016

Accepted December 5, 2016

Published February 23, 2017

DOI http://dx.doi.org/10.4238/gmr16019315

Copyright (C 2017 The Authors. This is an open-access article distributed under the terms of the Creative Commons Attribution ShareAlike (CC BY-SA) 4.0 License.

\begin{abstract}
The association between the interleukin-1 beta (IL1B) C-511T (or rs16944) polymorphism and periodontitis remains inconclusive, even though there have been previous studies on this association. To assess the effects of $I L-1 \beta \mathrm{C}-511 \mathrm{~T}$ variants on the risk of development of periodontitis, a meta-analysis was performed in a single ethnic population. Studies, published up to December 2015, were selected for the meta-analysis from PubMed and Chinese databases. The associations were assessed with pooled OR and 95\%CI. This meta-analysis identified 8 studies, including 1276 periodontitis cases and 1558 controls. Overall, a significant association between the $I L$ $1 \beta \mathrm{C}-511 \mathrm{~T}$ polymorphism and periodontitis was found in the Chinese population $(\mathrm{TT} v s \mathrm{CC}: \mathrm{OR}=1.48,95 \% \mathrm{CI}=1.19-1.85$; $\mathrm{TT}+\mathrm{CT} v s$ $\mathrm{CC}: \mathrm{OR}=1.50,95 \% \mathrm{CI}=1.25-1.81$; $\mathrm{T}$ vs $\mathrm{C}: \mathrm{OR}=1.33,95 \% \mathrm{CI}=1.06-$
\end{abstract}

Genetics and Molecular Research 16 (1): gmr16019315 
1.68). In the subgroup analyses based on geographical area(s), source of controls, and type of periodontitis, significant results were obtained for the association between $I L-1 \beta$ C-511T variants and periodontitis. Our meta-analysis indicated that the $I L-1 \beta \mathrm{C}-511 \mathrm{~T}$ polymorphism may be a genetic susceptibility factor for periodontitis in the Chinese population. This marker could be used to identify Chinese individuals at a high risk for periodontitis.

Key words: Meta-analysis; Interleukin-1 beta; Polymorphism; Periodontitis; Gene; Chinese

\section{INTRODUCTION}

Periodontal disease is an infection of the teeth and includes chronic and aggressive forms of the disease (Armitage, 1999). It is a broad and complex inflammatory disease, with a high prevalence of $10-15 \%$ (Albandar and Rams, 2002). Periodontitis is a multi-factorial disease, involving both genetic and environmental risk factors. Many researchers have agreed that the susceptibility to periodontal disease is at least partially genetically determined (Seymour, 1991). In recent years, many candidate genes have been identified as potential periodontitis susceptibility loci. Of these genes, an important gene is the interleukin-1 beta $(I L-1 \beta)$, which has three polymorphisms based on transitions between $\mathrm{C}$ and $\mathrm{T}$ at positions $+3954 / 3953(\mathrm{C} \rightarrow \mathrm{T}$, rs1143634), $-511(\mathrm{C} \rightarrow \mathrm{T}$, rs16944), and $-31(\mathrm{~T} \rightarrow \mathrm{C}$, rs1143627) base pairs from the transcription site (Bird et al., 2002; Xu et al., 2013, Yin et al., 2016). The $I L-1 \beta$ C-511T single nucleotide polymorphism has been extensively studied. Kornman et al. (1997) conducted the first ever study investigating the relationship between the $I L-1 \beta$ C-511T polymorphism and periodontal diseases in a population of European-descent (Kornman et al., 1997). Consequently, many studies have been conducted to attempt to clarify this relationship; however, there has been no definite consensus to date. Differences in results may be owing to the race and clinical heterogeneity of patients, as well as a limitation in the number of patients per study. Meta-analysis is one way to overcome the problems of small sample sizes and inadequate statistical power. To address the association between the $I L-1 \beta$ C-511T polymorphism and periodontitis risk further, we performed a meta-analysis of all eligible studies based on Chinese individuals to lessen the influence of different genetic backgrounds. We also performed a subgroup analysis to explore the possible effects of gene-environment interaction on the risk of periodontitis.

\section{MATERIAL AND METHODS}

\section{Search strategy and selection criteria}

Eligible studies were identified by searching the PubMed and Chinese databases for relevant reports published before December 2015 using the following search terms: periodontitis or periodontal disease, interleukin- 1 beta or $I L-1 \beta$, and China or Chinese or Taiwan. No restriction was imposed on the search term language. Furthermore, references cited in the retrieved articles were screened for additional relevant studies.

Inclusion criteria: 1) case-control or cohort studies describing the association of the $I L-1 \beta$ C-511T polymorphism with periodontitis, 2) studies that provided information about

Genetics and Molecular Research 16 (1): gmr16019315 
the genotypes of cases and controls, 3) Chinese participants. Exclusion criteria: 1) repeated literature, 2) incomplete data, 3) case-only articles, 4) review articles and abstracts, 5) participants with systemic diseases.

\section{Data extraction}

We conducted a systematic review and meta-analysis in accordance with the guidelines provided by the Preferred Reporting Items for Systematic Reviews and MetaAnalyses statement. Two authors independently extracted information from all publications that complied with the inclusion criteria. Disagreements were resolved by discussion. First, the titles and abstracts of all identified studies were screened. Full articles were scrutinized if the title and abstract were ambiguous. Data extracted from the selected studies included first author's name, year of publication, type of periodontitis, source of controls, geographical area(s), sample size, and the number of subjects with the $I L-1 \beta$ C-511T genotype. HardyWeinberg equilibrium (HWE), in controls, was calculated from the corresponding genotype distributions. In this meta-analysis, the quality assessment of individual studies was conducted according to the nine-star Newcastle-Ottawa Scale (Wells et al., 2000).

\section{Statistical analysis}

Statistical analysis was conducted using the Stata 10 statistical software package (StataCorp LP, College Station, TX, USA). The chi-square test was used for determining the HWE of genotypes and the heterogeneity of rare allele frequencies in the control groups of each study reviewed. The association of the $I L-1 \beta \mathrm{C}-511 \mathrm{~T}$ polymorphism with periodontitis risk was estimated by OR with $95 \%$ CI. Depending on the results of the heterogeneity test among individual studies, the fixed-effects (Mantel-Haenszel) or random-effects (DerSimonian and Laird) models were selected to summarize the combined OR and their $95 \%$ CI. The significance of the pooled OR was determined by a Z-test, and the sensitivity was analyzed by comparing the results of the fixed-effects and random-effects models. The publication bias was assessed using the Begg rank correlation method. In addition to the comparison among all subjects, we also performed stratification analyses by geographical area(s), source of controls, and type of periodontitis. All the P values were two-sided, and a value of less than 0.05 was considered statistically significant.

\section{RESULTS}

\section{Description of included studies}

Figure 1 illustrates the literature search process in the form of a flow chart. We identified 207 articles that examined the association between the $I L-1 \beta$ polymorphisms and the risk of periodontitis from various databases. After screening the titles and abstracts, 196 articles were excluded according to the exclusion criteria described previously. Then, we reviewed all of the remaining full articles (Huang and Zhang, 2004; Zhang et al., 2004; Yang, 2008; Fan, 2009; Zhang, 2009; Li et al., 2004, 2005, 2010; Loo et al., 2012; Hao et al., 2013; Wu et al., 2015). Out of the full articles, two (Li et al., 2005; Hao et al., 2013) were excluded because of duplicate studies and one (Wu et al., 2015) for lack of raw data. Finally, 8 articles

Genetics and Molecular Research 16 (1): gmr16019315 
(Huang and Zhang, 2004; Zhang et al., 2004; Yang, 2008; Fan, 2009; Zhang, 2009; Li et al., 2004, 2010; Loo et al., 2012) met the inclusion criteria completely. The publication years of these studies ranged from 2004 to 2012. In total, 1276 periodontitis cases and 1558 controls were included in this meta-analysis. The sources of controls in five studies were populationbased. Characteristics of the included studies are summarized in Table 1.

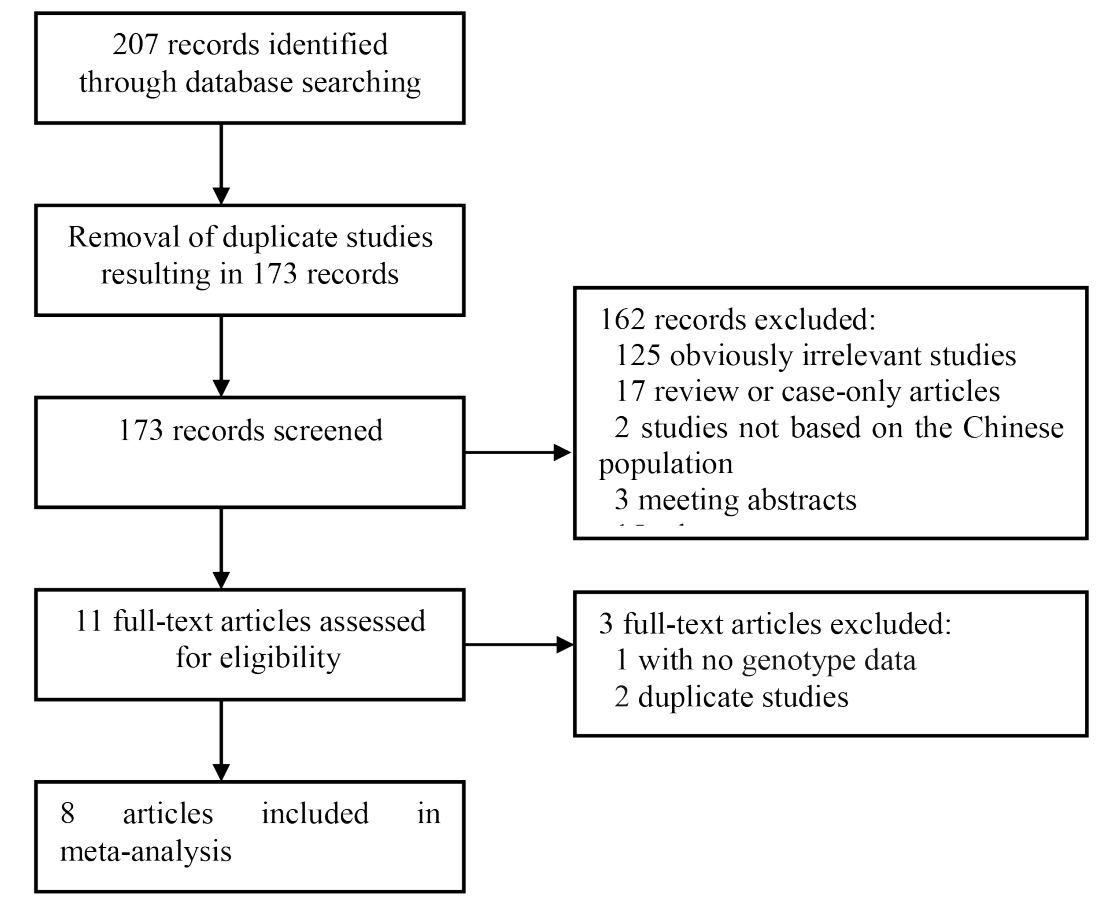

Figure 1. Flow diagram of the literature searching process.

\section{Table 1. Characteristics of studies included in the meta-analysis.}

\begin{tabular}{|c|c|c|c|c|c|c|c|c|c|c|c|c|c|c|}
\hline \multirow[t]{2}{*}{ References } & \multirow{2}{*}{\begin{tabular}{|c|} 
Type of \\
periodontitis
\end{tabular}} & \multirow{2}{*}{$\begin{array}{c}\begin{array}{c}\text { Source of } \\
\text { controls }\end{array} \\
\end{array}$} & \multirow{2}{*}{\begin{tabular}{|c} 
Quality \\
score
\end{tabular}} & \multirow{2}{*}{$\begin{array}{c}\text { Geographical } \\
\text { area(s) }\end{array}$} & \multirow{2}{*}{$\begin{array}{c}\text { Number of } \\
\text { cases }\end{array}$} & \multirow{2}{*}{$\begin{array}{c}\begin{array}{c}\text { Number of } \\
\text { controls }\end{array} \\
\end{array}$} & \multicolumn{3}{|c|}{ Cases } & \multicolumn{3}{|c|}{ Controls } & \multicolumn{2}{|c|}{ HWE } \\
\hline & & & & & & & $\mathrm{CC}$ & CT & TT & $\mathrm{CC}$ & CT & TT & $\chi^{2}$ & $P$ \\
\hline Li et al. (2004) & $\mathrm{AP}$ & $\mathrm{PB}$ & 8 & Beijing & 122 & 95 & 33 & 55 & 34 & 28 & 44 & 23 & 0.48 & 0.488 \\
\hline Huang and Zhang (2004) & $\mathrm{CP}$ & HB & 7 & Sichuan & 182 & 89 & 25 & 58 & 99 & 21 & 49 & 19 & 0.92 & 0.337 \\
\hline Zhang et al. (2004) & $\mathrm{CP}$ & PB & 7 & Xinjiang & 128 & 130 & 36 & 52 & 40 & 37 & 53 & 40 & 4.41 & 0.036 \\
\hline Yang (2008) & $\mathrm{CP}$ & PB & 6 & Xinjiang & 44 & 49 & 11 & 20 & 13 & 18 & 21 & 10 & 0.70 & 0.403 \\
\hline Fan (2009) & $\mathrm{CP}$ & PB & 8 & \begin{tabular}{|l} 
Guangdong \\
\end{tabular} & 177 & 139 & 41 & 78 & 58 & 36 & 67 & 36 & 0.18 & 0.671 \\
\hline Zhang (2009) & $\mathrm{CP}$ & $\mathrm{HB}$ & 8 & Lanzhou & 103 & 126 & 24 & 54 & 25 & 38 & 61 & 27 & 0.07 & 0.785 \\
\hline Li et al. (2010) & $\mathrm{CP}$ & $\mathrm{HB}$ & 6 & Liaoning & 80 & 80 & 16 & 36 & 28 & 34 & 26 & 20 & 8.68 & 0.003 \\
\hline 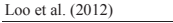 & $\mathrm{CP}$ & PB & 8 & Sichuan & 440 & 850 & 61 & 251 & 128 & 179 & 357 & 314 & 16.25 & 0.000 \\
\hline
\end{tabular}

$\mathrm{PB}=$ population-based $\mathrm{HB}=$ hospital-based; $\mathrm{CP}=$ chronic periodontitis; $\mathrm{AP}=$ aggressive periodontitis; $\mathrm{HWE}=$ Hardy-Weinberg equilibrium.

\section{Meta-analysis}

Table 2 lists the primary results of our meta-analysis. The combined results showed that $I L-1 \beta \mathrm{C}-511 \mathrm{~T}$ variants are significantly associated with an increased risk of periodontitis in the Chinese population (for TT $v s \mathrm{CC}$ : $\mathrm{OR}=1.48,95 \% \mathrm{CI}=1.19-1.85$; for TT $+\mathrm{CT} v_{s} \mathrm{CC}$ :

Genetics and Molecular Research 16 (1): gmr16019315 
$\mathrm{OR}=1.50,95 \% \mathrm{CI}=1.25-1.81$; for $\left.\mathrm{T} v_{s} \mathrm{C}: \mathrm{OR}=1.33,95 \% \mathrm{CI}=1.06-1.68\right)$ (Figure 2). In the analysis of controls based on consistency with HWE, we obtained significant results among all the models ( $\mathrm{T}$ vs $\mathrm{C}, \mathrm{OR}=1.43,95 \% \mathrm{CI}=1.06-1.94$; $\mathrm{TT}$ vs $\mathrm{CC}, \mathrm{OR}=1.78,95 \% \mathrm{CI}=1.27$ 2.48; $\mathrm{TT}+\mathrm{CT} v s \mathrm{CC}, \mathrm{OR}=1.37,95 \% \mathrm{CI}=1.04-1.81 ; \mathrm{TT}$ vs $\mathrm{CC}+\mathrm{CT}, \mathrm{OR}=1.71,95 \% \mathrm{CI}=$ 1.02-2.85) (Table 2). In subgroup analyses based on geographical area(s), source of controls, and type of periodontitis, significant results for the association between $I L-1 \beta \mathrm{C}-511 \mathrm{~T}$ variants and periodontitis were obtained (Table 2). Cumulative analysis further suggested a significant association between the $I L-1 \beta \mathrm{C}-511 \mathrm{~T}$ polymorphism and the risk of periodontitis in the Chinese population (Figure 3).

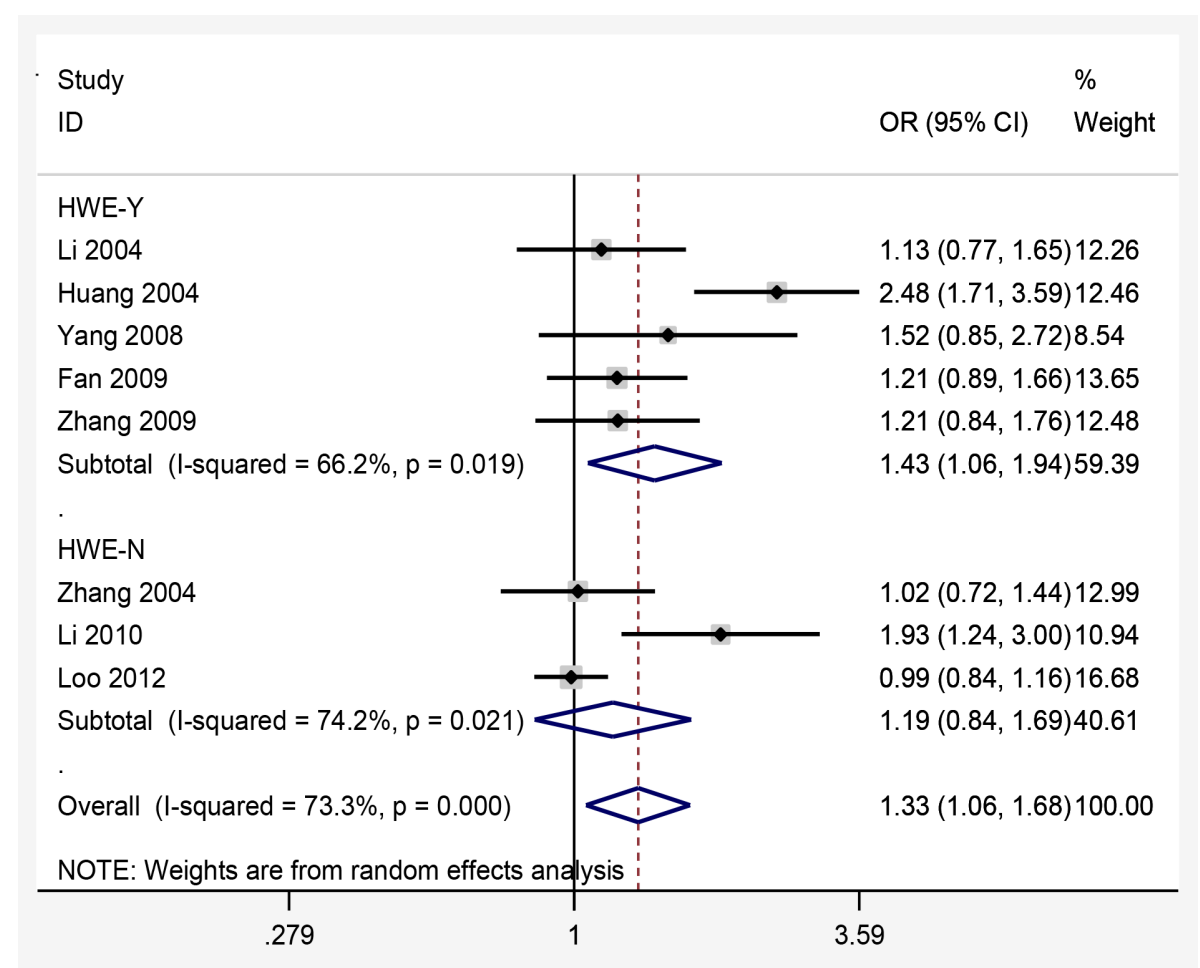

Figure 2. Forest plots of all selected studies on the association between the $I L-1 \beta$ C-511T polymorphism and periodontitis risk in the Chinese population (for allele model). HWE: Hardy-Weinberg equilibrium.

\section{Sensitivity analysis and publication bias}

In order to compare the differences and evaluate the sensitivity of the analyses, we used both models (the fixed-effects model and random-effects model) to determine the stability of this meta-analysis. All the significant pooled OR did not materially alter, suggesting that the results of this meta-analysis are stable (Table 2). The Begg rank correlation method was performed to assess the publication bias in the allele model. No evidence of publication bias was observed $(\mathrm{P}=0.138)$. 


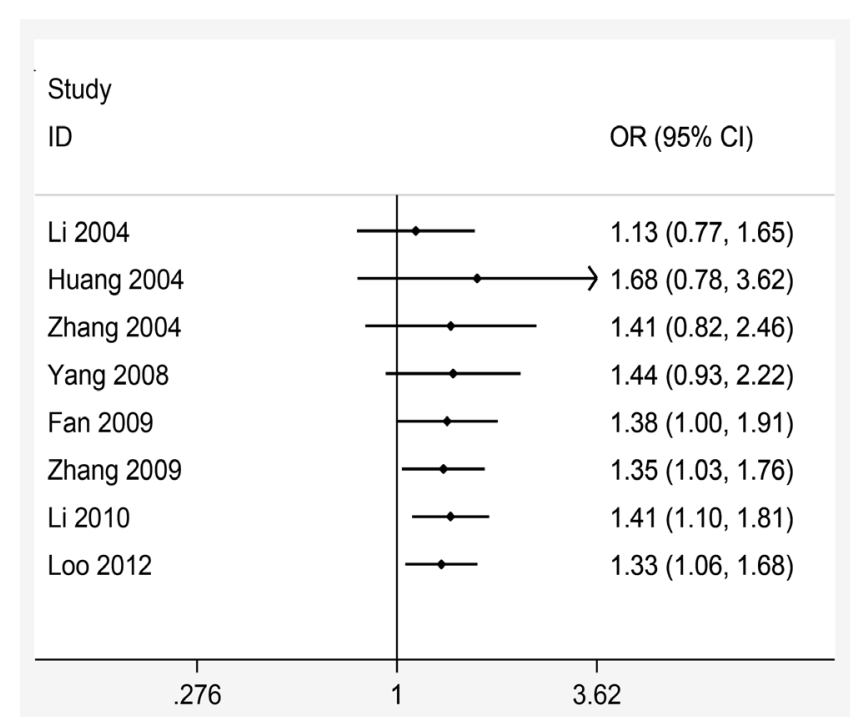

Figure 3. Cumulative analysis of the relationship between the $I L-1 \beta \mathrm{C}-511 \mathrm{~T}$ polymorphism and periodontitis risk in the Chinese population (for allele model).

Table 2. Association of $I L-1 \beta$ C-511T polymorphism with periodontitis susceptibility.

\begin{tabular}{|c|c|c|c|c|c|}
\hline \multicolumn{2}{|l|}{ Analysis model } & $\mathrm{N}$ & $\mathrm{ORr}(95 \% \mathrm{CI})$ & ORf $(95 \% \mathrm{CI})$ & $\mathrm{P}_{\mathrm{h}}$ \\
\hline \multirow[t]{7}{*}{$\mathrm{T} v s \mathrm{C}$} & Total analysis & 8 & $1.33(1.06-1.68)$ & $1.19(1.07-1.33)$ & 0.000 \\
\hline & In HWE & 5 & $1.43(1.06-1.94)$ & $1.42(1.19-1.68)$ & 0.019 \\
\hline & Population-based & 5 & $1.06(0.93-1.20)$ & $1.06(0.93-1.20)$ & 0.543 \\
\hline & Hospital-based & 3 & $1.79(1.16-2.77)$ & $1.77(1.42-2.22)$ & 0.026 \\
\hline & North China & 5 & $1.27(1.02-1.59)$ & $1.26(1.05-1.50)$ & 0.217 \\
\hline & South China & 3 & $1.41(0.85-2.33)$ & $1.16(1.01-1.33)$ & 0.000 \\
\hline & $\mathrm{CP}$ & 7 & $1.37(1.05-1.78)$ & $1.20(1.07-1.34)$ & 0.000 \\
\hline \multirow[t]{7}{*}{ TT vs CC } & Total analysis & 8 & $1.63(1.17-2.28)$ & $1.48(1.19-1.85)$ & 0.054 \\
\hline & In HWE & 5 & $1.84(1.16-2.91)$ & $1.78(1.27-2.48)$ & 0.127 \\
\hline & Population-based & 5 & $1.24(0.97-1.60)$ & $1.24(0.97-1.60)$ & 0.835 \\
\hline & Hospital-based & 3 & $2.66(1.39-5.08)$ & $2.59(1.66-4.05)$ & 0.124 \\
\hline & North China & 5 & $1.51(1.04-2.20)$ & $1.50(1.06-2.11)$ & 0.329 \\
\hline & South China & 3 & $1.83(0.91-3.68)$ & $1.48(1.11-1.96)$ & 0.010 \\
\hline & $\mathrm{CP}$ & 7 & $1.71(1.17-2.50)$ & $1.51(1.20-1.90)$ & 0.035 \\
\hline \multirow[t]{7}{*}{$\mathrm{TT}$ vs $\mathrm{CC}+\mathrm{CT}$} & Total analysis & 8 & $1.38(0.90-2.13)$ & $1.09(0.93-1.28)$ & 0.000 \\
\hline & In HWE & 5 & $1.71(1.02-2.85)$ & $1.75(1.34-2.28)$ & 0.010 \\
\hline & Population-based & 5 & $1.05(0.74-1.49)$ & $0.89(0.74-1.07)$ & 0.048 \\
\hline & Hospital-based & 3 & $2.05(0.91-4.62)$ & $2.18(1.53-3.09)$ & 0.006 \\
\hline & North China & 5 & $1.24(0.93-1.65)$ & $1.24(0.93-1.65)$ & 0.836 \\
\hline & South China & 3 & $1.58(0.56-4.44)$ & $1.02(0.84-1.25)$ & 0.000 \\
\hline & $\mathrm{CP}$ & 7 & $1.41(0.86-2.31)$ & $1.08(0.91-1.28)$ & 0.000 \\
\hline \multirow[t]{7}{*}{$\mathrm{TT}+\mathrm{CT}$ vs $\mathrm{CC}$} & Total analysis & 8 & $1.49(1.20-1.85)$ & $1.50(1.25-1.81)$ & 0.290 \\
\hline & In HWE & 5 & $1.38(1.04-1.81)$ & $1.37(1.04-1.81)$ & 0.696 \\
\hline & Population-based & 5 & $1.37(1.10-1.70)$ & $1.38(1.11-1.71)$ & 0.456 \\
\hline & Hospital-based & 3 & $1.95(1.29-2.93)$ & $1.93(1.34-2.80)$ & 0.298 \\
\hline & North China & 5 & $1.45(1.01-2.10)$ & $1.42(1.07-1.88)$ & 0.171 \\
\hline & South China & 3 & $1.56(1.22-2.00)$ & $1.56(1.22-2.00)$ & 0.397 \\
\hline & $\mathrm{CP}$ & 7 & $1.54(1.22-1.95)$ & $1.55(1.27-1.88)$ & 0.273 \\
\hline
\end{tabular}

$\mathrm{ORr}=$ odds ratio for random-effects model; $\mathrm{ORf}=$ odds ratio for fixed-effects model; $\mathrm{P} \mathrm{P}=$ value for heterogeneity test; HWE = Hardy-Weinberg equilibrium; North China included Beijing, Lanzhou, Xinjiang, and Liaoning; South China included Sichuan and Guangdong.

Genetics and Molecular Research 16 (1): gmr16019315 


\section{DISCUSSION}

Periodontitis is a multifactorial and inflammatory disease that is mainly related to oral hygiene. Convincing evidence has emerged that susceptibility to periodontal disease is partially based on a genetic predisposition to the disease. The relationship between the $I L-1 \beta$ C-511T polymorphism and periodontitis risk has attracted the attention of both doctors and researchers. Ever since the first reported study on the association between the $I L-1 \beta \mathrm{C}-511 \mathrm{~T}$ polymorphism and chronic periodontitis in a population of European-descent (Kornman et al., 1997), many studies have been undertaken to explore this association. However, results of individual studies have been inconclusive. Regional and racial differences are the likely reasons for disparity in the results. Therefore, we performed this meta-analysis to assess the effects of the $I L-1 \beta$ C-511T polymorphism on the risk of periodontitis in the Chinese population.

Our meta-analysis included 8 case-control studies with 1276 periodontitis cases and 1558 controls. Results showed a significant association between the $I L-1 \beta$ C-511T polymorphism and periodontitis in the overall and subgroup analyses. Controls of two of the cohorts were not in HWE $(\mathrm{P}<0.05)$, including the Loo et al. (2012) cohort, which contributed more than $50 \%$ of the controls to the study. We further performed analyses based on consistency of controls with HWE, and the results showed a significant association between the $I L-1 \beta$ C-511T polymorphism and periodontitis risk. Cumulative meta-analysis also revealed a trend of an increasingly obvious association between $I L-1 \beta$ C-511T variant $\mathrm{T}$ and the risk of periodontitis in Chinese individuals as per data accumulated by publication year (Figure 3). The findings from this meta-analysis provide new and strong epidemiological evidence for the association between $I L-1 \beta \mathrm{C}-511 \mathrm{~T}$ variants and the risk of periodontitis in the Chinese population.

As compared to a previous meta-analysis by $\mathrm{Hu}$ et al. (2015), which included only one case-control study based on the Chinese population, our meta-analysis contained more studies using the Chinese population. Furthermore, in another meta-analysis conducted by Zeng et al. (2015), two of the studies (Loo et al., 2012; Hao et al., 2013) potentially involved the same subjects of the Chinese population. The present meta-analysis was strengthened by the exclusion of duplicated studies, and significant results were revealed in the subgroup and overall analyses. The effects of gene-environment interactions with respect to periodontitis risk were determined by subgroup analyses. Additionally, we were able to explore the relationship between the $I L-1 \beta C$ - $511 \mathrm{~T}$ polymorphism and the risk of periodontitis without the possible influence of differing genetic backgrounds and living environments on the results. Sensitivity analyses confirmed the reliability and stability of the meta-analysis. Therefore, our results indicated that the $I L-1 \beta \mathrm{C}-511 \mathrm{~T}$ polymorphism is associated with the susceptibility to periodontitis in individuals from China.

Although our study has strengths such as the investigation of the influence of geographical area(s) and source of control on the association between the $I L-1 \square \mathrm{C}-511 \mathrm{~T}$ polymorphism and the risk of periodontitis, there are several limitations as well. Firstly, this ethnicity-specific meta-analysis includes data of only Chinese subjects, and thus, our results are applicable to only this ethnic group. Secondly, since this meta-analysis was based primarily on unadjusted effect estimates and CI, confounding factors were not controlled. Thirdly, although we devised a comprehensive search strategy, relatively less number of studies complied with the inclusion criteria.

Genetics and Molecular Research 16 (1): gmr16019315 
In conclusion, this meta-analysis indicates that the $I L-1 \beta \mathrm{C}-511 \mathrm{~T}$ polymorphism is associated with the risk of periodontitis in the Chinese population. Ethnicity seems to play a role in the genetic association of the disease. Since the number of studies analyzed was less, further meta-analyses of larger populations with multiple adjusted variables need to be conducted to achieve robust results and allow for investigation of gene-gene and geneenvironment interactions.

\section{Conflicts of interest}

The authors declare no conflict of interest.

\section{ACKNOWLEDGMENTS}

Thanks to the Stomatology Center of Xiangya Hospital of Central South University and Changsha Stomatological Hospital. Thanks for their support in the application of databases.

\section{REFERENCES}

Albandar JM and Rams TE (2002). Global epidemiology of periodontal diseases: an overview. Periodontol. 2000 29: 7-10. http://dx.doi.org/10.1034/j.1600-0757.2002.290101.x

Armitage GC (1999). Development of a classification system for periodontal diseases and conditions. Ann. Periodontol. 4: 1-6. http://dx.doi.org/10.1902/annals.1999.4.1.1

Bird S, Zou J, Wang T, Munday B, et al. (2002). Evolution of interleukin-1beta. Cytokine Growth Factor Rev. 13: 483502. http://dx.doi.org/10.1016/S1359-6101(02)00028-X

Fan WH (2009). Investigation on polymorphisms of inierleukin-6 and interleukin-1 genes as the risk factors for coronary heart disease and chronic periodontitis. Doctoral Thesis, Department of Clinical Medicine, Southern Medical University, Guangzhou. (Chinese).

Hao L, Li JL, Yue Y, Tian Y, et al. (2013). Application of interleukin-1 genes and proteins to monitor the status of chronic periodontitis. Int. J. Biol. Markers 28: 92-99. http://dx.doi.org/10.5301/jbm.5000013

Hu YY, Liu JH, Jiang GB, Yuan RX, et al. (2015). Association between interleukin-1 $\beta$ gene $-511 \mathrm{C}>\mathrm{T} /+3954 \mathrm{C}>\mathrm{T}$ polymorphisms and aggressive periodontitis susceptibility: evidence from a meta-analysis. Med. Sci. Monit. 21: 1617-1624. http://dx.doi.org/10.12659/MSM.894402

Huang HY and Zhang JC (2004). Investigation on the association of interleukin-1 genotype polymorphism with chronic periodontitis. Hua Xi Kou Qiang Yi Xue Za Zhi 22: 415-419.

Kornman KS, Crane A, Wang HY, di Giovine FS, et al. (1997). The interleukin-1 genotype as a severity factor in adult periodontal disease. J. Clin. Periodontol. 24: 72-77. http://dx.doi.org/10.1111/j.1600-051X.1997.tb01187.x

Li N, Song JH, Su JR, Li KY, et al. (2010). Association of interleukin-1 beta 511C/T gene polymorphism with diabetes and chronic periodontitis. Shangdong Yi Yao 50: 71-72.

Li QY, Zhao HS, Meng HX, Zhang L, et al. (2004). Association analysis between interleukin-1 family polymorphisms and generalized aggressive periodontitis in a Chinese population. J. Periodontol. 75: 1627-1635. http://dx.doi. org/10.1902/jop.2004.75.12.1627

Li QY, Zhao HS, Meng HX, Zhang L, et al. (2005). Association analysis between interleukin-1 $\beta-511$ polymorphism and aggressive periodontitis. Zhongguo Yousheng Yu Yichuan Zazhi 13: 22-24.

Loo WT, Fan CB, Bai LJ, Yue Y, et al. (2012). Gene polymorphism and protein of human pro- and anti-inflammatory cytokines in Chinese healthy subjects and chronic periodontitis patients. J. Transl. Med. 10 (Suppl 1): S8. http:// dx.doi.org/10.1186/1479-5876-10-S1-S8

Seymour GJ (1991). Importance of the host response in the periodontium. J. Clin. Periodontol. 18: 421-426. http://dx.doi. org/10.1111/j.1600-051X.1991.tb02310.x

Wells GA, Shea B, O'Connell D, Peterson J, et al. (2000). The Newcastle-Ottawa Scale (NOS) for assessing the quality of nonrandomized studies in meta-analyses. Available at [http://www.ohri.ca/programs/clinical_epidemiology/oxford.asp].

Wu X, Offenbacher S, López NJ, Chen D, et al. (2015). Association of interleukin-1 gene variations with moderate to severe chronic periodontitis in multiple ethnicities. J. Periodontal Res. 50: 52-61. http://dx.doi.org/10.1111/jre.12181

Genetics and Molecular Research 16 (1): gmr16019315 
Xu J, Yin Z, Cao S, Gao W, et al. (2013). Systematic review and meta-analysis on the association between IL-1B polymorphisms and cancer risk. PLoS One 8: e63654. http://dx.doi.org/10.1371/journal.pone.0063654

Yang K (2008). Interleukin-1 genotype and the association between chronic periodontitis and coronary heart disease. Master's Thesis, Department of Oral Clinical Medicine,Urumqi Xinjiang Medical University, Urumqi. (Chinese)

Yin WT, Pan YP and Lin L (2016). Association between IL-1 $\alpha$ rs17561 and IL-1 $\beta$ rs 1143634 polymorphisms and periodontitis: a meta-analysis. Genet. Mol. Res. 15: 1. http://dx.doi.org/10.4238/gmr.15017325

Zeng XT, Liu DY, Kwong JS, Leng WD, et al. (2015). Meta-analysis of association between interleukin-1 $\beta$ C-511T polymorphism and chronic periodontitis susceptibility. J. Periodontol. 86: 812-819. http://dx.doi.org/10.1902/ jop. 2015.140698

Zhang L (2009). The association of interleukin-1 gene polymorphisms with the susceptibility to chronic periodontitis in Dongxiang Populations from Northwestern China. Master's thesis, Department of Botany, Lanzhou University, Lanzhou. (Chinese)

Zhang YM, Zhong LJ, Gulibositan D, Nie J, et al. (2004). Interleukin-1 B-511 genotype and the association between chronic periodontitis and coronary heart disease. Xinjiang Yike Daxue Xuebao 27: 202-204.

Genetics and Molecular Research 16 (1): gmr16019315 